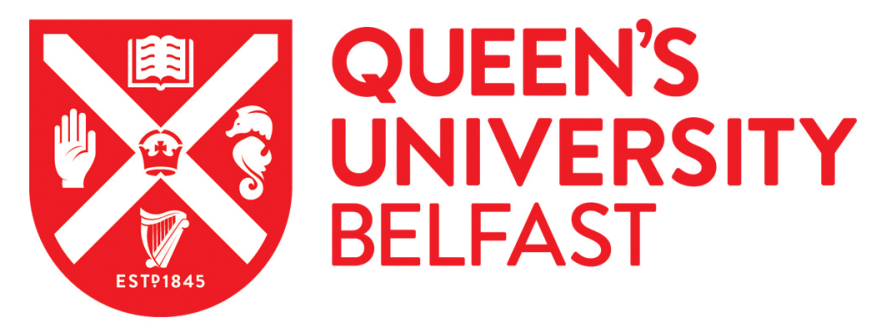

\title{
Factors affecting Effectiveness of Agile Usage - Insights from the BBC Worldwide Case Study
}

Middleton, P., \& Senapathi, M. (2011). Factors affecting Effectiveness of Agile Usage - Insights from the BBC Worldwide Case Study. 132-145. Paper presented at Agile Processes in Software Engineering and Extreme Programming, Madrid, Spain.

Queen's University Belfast - Research Portal:

Link to publication record in Queen's University Belfast Research Portal

\section{General rights}

Copyright for the publications made accessible via the Queen's University Belfast Research Portal is retained by the author(s) and / or other copyright owners and it is a condition of accessing these publications that users recognise and abide by the legal requirements associated with these rights.

Take down policy

The Research Portal is Queen's institutional repository that provides access to Queen's research output. Every effort has been made to ensure that content in the Research Portal does not infringe any person's rights, or applicable UK laws. If you discover content in the Research Portal that you believe breaches copyright or violates any law, please contact openaccess@qub.ac.uk. 


\title{
Factors Affecting Effectiveness of Agile Usage - Insights from the BBC Worldwide Case Study
}

\author{
Mali Senapathi ${ }^{1}$, Peter Middleton ${ }^{2}$, and Gareth Evans ${ }^{3}$ \\ ${ }^{1}$ Auckland University of Technology, New Zealand \\ mali.senapathi@aut.ac.nz \\ ${ }^{2}$ Queen's University Belfast, Northern Ireland \\ p.middleton@qub.ac.uk \\ ${ }^{3}$ Assurity Consulting Limited, New Zealand \\ gareth.evans@assurity.co.nz
}

\begin{abstract}
The past decade has seen significant changes in systems development with many organizations adopting agile methodologies as a viable methodology for developing systems. An increasing number of research studies reveal the growing popularity and acceptance of agile methodologies. While most academic research has focused on adoption and adaptation of agile methods, there is very limited understanding of their post-adoption usage and incorporation within organizations. What factors explain the effective usage of agile methodologies? A synthesis of past research in Systems Development Methodologies, Information Systems implementation, Diffusion of Innovations, and Agile Methodologies was conducted to develop a research model that identifies the main factors pertinent to the propagation and effective usage of agile methodologies in organizations. The model is tested by applying it to the usage of Kanban for Software Engineering practices at BBC Worldwide, London. Insights gained from the case study are discussed.
\end{abstract}

Keywords: Agile usage, effectiveness of agile usage, Kanban.

\section{Introduction}

Agile methodologies (AM) emerged as a popular alternative to address the problems inherent in established methods to systems development [1]. AM have gained widespread acceptance in both the academic and industrial contexts with an increasing number of studies reporting their high adoption and success rates [2, 3] over the past decade. However, most academic research has mainly focused on the adoption and adaptation of agile methods [4]. Moreover, they offer a very broad range of experiences without providing a unified view of current practice [2], which suggest that there is an imprecise understanding of their use and practice in organizations beyond the adoption phase. This discrepancy may be explained in a number of ways. One explanation is that most organizations that have adopted agile methods are still trialling on a project by project basis, and their routinized use and spread throughout the organization is yet to happen. Moreover, researchers have highlighted the lack of quality and decreasing reliability in the findings of agile 
empirical studies in the literature [2]. More research is therefore needed into understanding the actual practice of AM in organisations.

According to [5], diffusion of innovations is a six-staged process comprising initiation, adoption, adaptation, acceptance, use, and incorporation. While studies on the initial phases (initiation, adoption, adaptation) provide insights into the early phases of diffusion of an innovation, studies that focus on the later stages of diffusion provide valuable insights into how an innovation can be effectively propagated within the organization. Therefore, the factors which drive an Information Systems (IS) innovation varies across different implementation phases [6]. Moreover, since AM denote a radical departure from traditional systems development approaches, they bring with them a host of new challenges which encompass various social, technical and organizational aspects [7-9]. With a change in the primary approach to systems development it is expected that there will be substantial changes in the systems development process, which in turn will have an impact on the various factors that will affect agile adoption and use during the different implementation phases. We need to be able to identify these set of factors that might influence its continued and effective usage in organizations. Therefore the key research questions guiding this study are: How can agile usage effectiveness be measured? What are the factors that affect agile usage effectiveness?

Most studies that report higher adoption rates and success of agile methods do not define, much less measure 'effectiveness' of the usage of agile practices or identify the factors that affect effectiveness. The answers to these questions lie in research to evaluate the post-adoption use of agile methods. This implies that there is an increasing need for a better understanding beyond the adoption stage as many organizations have completed adoption and agile methods have started to become well-established processes of these organizations [1]. A better understanding of the various factors that affect successful incorporation of agile methods is believed to provide valuable insights from at least three perspectives: a) provide new theoretical insights into the factors affecting the effectiveness of agile usage, b) improve our understanding of post adoption use, processes and impact of agile methodologies, and c) contribute to industrial practice by providing insights into how agile methods can be effectively used in organizations.

Given that the usage of agile methodologies is a versatile concept, the current study draws from well-established theories such as diffusion of innovations and IS implementation research which have been extensively used throughout the IS literature to explain the constructs relating to the adoption and implementation of new IS innovations. The next section summarizes this literature and presents a conceptual framework based on innovation, sociological, technological, team and organisational factors influencing the effective usage of agile methodologies in organisations. We then outline the research design used in the study before presenting the results and analysis of the case study. The final part concludes with some implications for research and practice.

\section{Theoretical Background and the Research Framework}

The definition adopted for usage in the present study is similar to that proposed by [10] who suggests that acceptance is preceded by, and based on, usage of the 
innovation beyond the pilot project stage, i.e., Usage -> Acceptance -> Incorporation, where usage is specified using two measures: horizontal usage - concerned with the use of the innovation across the organization, and vertical usage - concerned with the depth of usage. Applying these definitions' to the context of agile methodologies, Horizontal Usage is defined as the overall use of agile practices across the organization- for example, percentage of projects and developers/analysts using agile practices, and Vertical Usage is defined as the maximum intensity of their use, i.e., depth of use of specific agile values, practices, and policies.

In software development, terms such as 'agile' or 'agile methodology' commonly refers to one of the major agile methods such as extreme programming (XP), featuredriven development, crystal method, Scrum, and dynamic systems development method - each of which prescribes a set of core practices, values and principles. However, in practice, most organizations do not strictly follow or adhere to any one particular agile method, but use a tailored approach by combining a number of good agile practices from different agile methods that best suits their contextual requirements, "if you dumped all these good practices out onto a table, you'd have quite a buffet of very good practices with which to tailor your own process. And that's exactly what most organizations do" [11]. Therefore, in the current study, agile usage does not refer to one particular agile method such as Scrum but rather to the continued usage of agile practices, where practices might include combination of practices from $\mathrm{XP}$ and Scrum, or implementing the core properties of a kanban system while continuing to use some XP and Scrum practices.

Table 1. Factors expected to relate to agile usage and agile usage effectiveness

\begin{tabular}{|c|c|c|c|}
\hline \multicolumn{2}{|c|}{ Theoretical factors } & Agile Usage & Agile Usage \\
\hline \multirow[t]{2}{*}{ Agile innovation } & Relative advantage & \multirow{6}{*}{$\begin{array}{l}\text { Horizontal } \\
\text { usage }\end{array}$} & \multirow{9}{*}{ 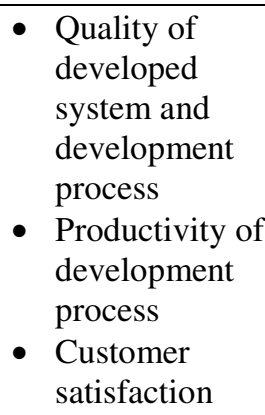 } \\
\hline & Compatibility & & \\
\hline \multirow[t]{2}{*}{ Sociological } & Experience & & \\
\hline & Knowledge/expertise & & \\
\hline \multirow[t]{2}{*}{ Technological } & Agile practices & & \\
\hline & Tool support & & \\
\hline \multirow[t]{2}{*}{ Team } & Team management & \multirow[t]{3}{*}{ Vertical usage } & \\
\hline & $\begin{array}{l}\text { Methodology } \\
\text { champion }\end{array}$ & & \\
\hline Organizational & Management support & & \\
\hline
\end{tabular}

Based on a synthesis of past research in diffusion of innovations, IS implementation, and agile implementation literature, five groups of factors potentially affecting Agile Usage were identified: (1) Agile innovation factors (relative advantage, compatibility) mainly adopted from the innovation diffusion literature, (2) Sociological factors (experience level, Knowledgelexpertise (domain expertise, language expertise, etc.,) adopted from eXtreme Programming (XP) evaluation framework [12], (3) Technological factors (agile practices, tool support (project management/use of automation tools) adopted from XP evaluation framework [12], (4) Team factors 
(team management, methodology champion) adopted from XP literature, and (5) Organizational factors (top management support) adopted from the IS implementation literature. Table 1 summarizes the different perspectives examined under each of the implementation factors in terms of their relationship to the degree of agile usage and its effectiveness.

The resulting conceptual framework is depicted in Figure 1.

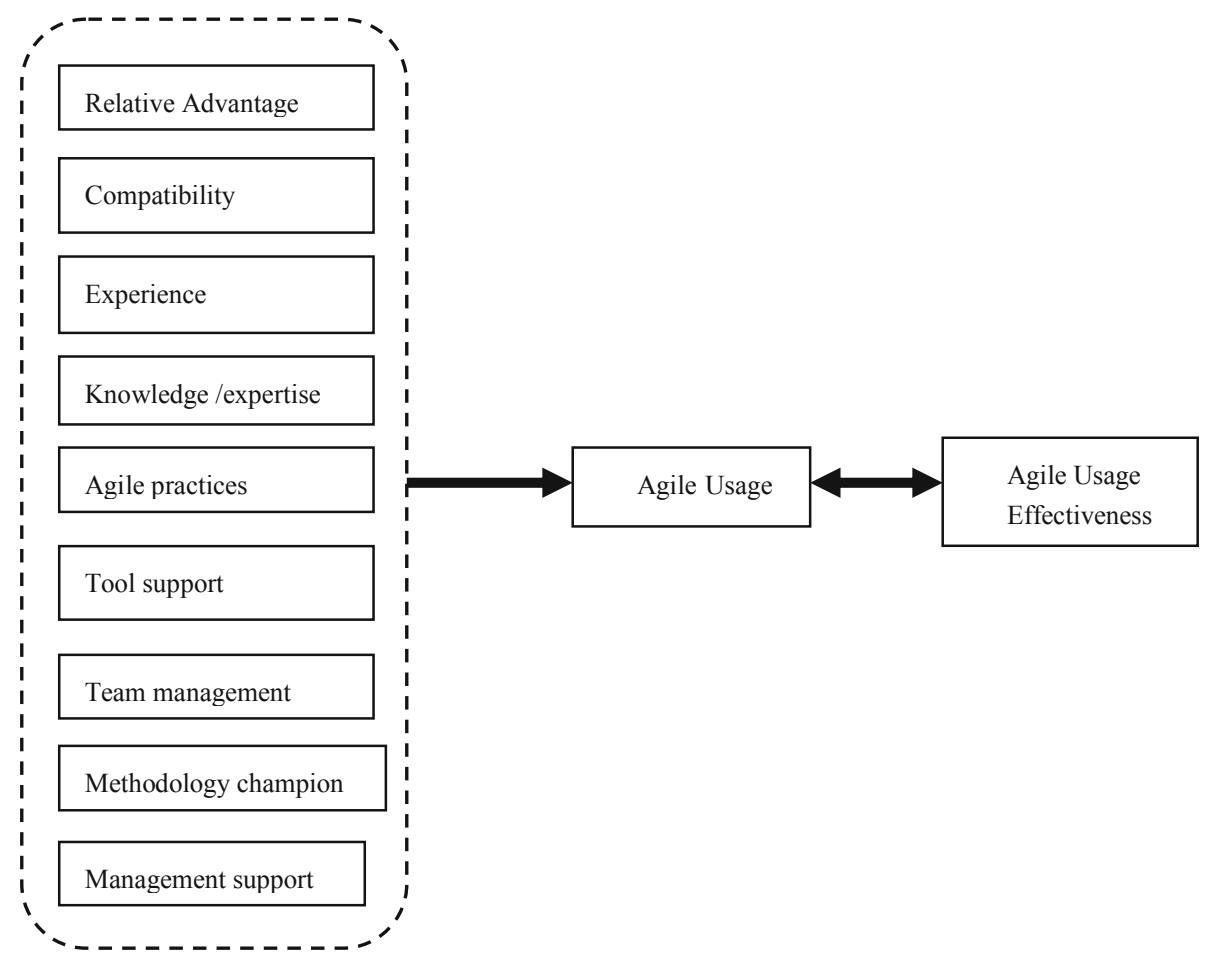

Fig. 1. The research framework

We now briefly discuss the theoretical rationale for the consideration of these factors and their influence on agile usage and its effectiveness.

\section{Innovation factors}

Relative advantage: the degree to which the innovation is perceived better than its precursor [13]. There is sufficient empirical evidence to suggest that relative advantage is a significant factor in predicting the usage of Systems Development Methodologies [14, 15]. In the context of agile methods, relative advantage would refer to the degree to which the chosen agile practices are found to better meet the contextual needs of the project and provide specific benefits such as increased productivity, improved quality, reduced time and costs, and higher customer satisfaction in comparison to its precursor practices. 
Compatibility: the degree to which the innovation is perceived as being consistent with the existing values, needs, and past experiences of adopters [13]. Since the adoption of agile methods represents a major shift in the paradigm of systems development [16], it entails major alterations to work practices, investment in tools that support and facilitate rapid iterative development, versioning/configuration management, JUnits, refactoring and other agile techniques [9]. In terms of postimplementation stages, compatibility is described as the fit between an innovation and a particular context [10], which implies that the chosen agile practices must match its context in order to be effective and successfully infused in the organization. For example, [4] found that the use of multiple languages such as Java, $\mathrm{C}++$, and Motif, in a large legacy project caused serious challenges to the adoption of XP practices such as code ownership, refactoring, and automated testing.

\section{Sociological factors}

Though organizations play a significant role in adopting contemporary innovations such as agile methods/practices, their acceptance and continued usage beyond the adoption stage really depends on the actual users/teams who use the practices to develop software $[17,18]$. Some of the specific individual sociological factors that impact usage include attitude, experience, technical knowledge and expertise [19].

Experience: People with the right attitude and experience will embrace the newer practices easily and faster, and high level of team experience is said to contribute to increased productivity [12].

Knowledge/Expertise: Users and teams with high levels of technical expertise in terms of programming languages, different application domains, and other related software development technical practices, may not be subject to the learning curve associated with an unfamiliar domain, or with learning an unfamiliar programming language [12].

\section{Technological factors}

Agile practices: There is often a substantial difference between the textbook 'vanilla' version and the actual "method-in-action" used in practice as most prescribed practices are tailored to meet the contextual needs of software development [20, 21]. For example, [20] found that different XP practices reached different levels of assimilation at different periods of usage, and practices that addressed specific needs of the adopting team reached deeper assimilation levels.

Tool support: While the significance of tool support in the adoption of software process innovations in general has been recognized [22], their importance in facilitating the acceptance of agile practices in terms of providing support in adhering to specific XP practices such as refactoring, continuous integration, and test-driven development is also documented [4].

\section{Team factors}

Given the increasingly important role of teams in agile software development, team characteristics and practices that facilitate the use of agile methods are more likely to affect their effective use. 
Team Management: team practices that empower the team to be more autonomous and key decision-makers in deciding project scope, schedule, and choice of tasks, tools, practices etc., are deemed critical in facilitating the acceptance and continued usage of agile practices [4].

Methodology Champion: Any innovative idea or practice without a champion is not likely to succeed [23]. In the context of AM, methodology champions play the significant role of change agents in encouraging and facilitating the on-going usage of agile practices [24], which include responsibilities such as mentoring, and ensuring that agile practices are strictly followed and adhered to by team members [4].

\section{Organizational factors}

Top Management support: Top Management support refers to ongoing, continual support and encouragement of the top management executives in the adoption and implementation of innovations [25], and is one of the main organizational factors that is consistently reported to facilitate systems development methodology implementation [15]. Lack of management support and interest has been found to be one of the biggest obstacles in implementing systems development methodologies [26] and successful diffusion of agile methods/practices [3].

\section{Research Design}

A case study methodology was employed in this study because it enables investigation of a contemporary phenomenon within its natural setting [27], and is especially appropriate for newer topic areas such as post-adoption use or assimilation of agile practices, where theory and research are still in their early formative stages [28, 29].

The data collected mainly involved interviews with the members of the Digital Hub (Digi-Hub) development team that was involved with the implementation of Kanban at BBC Worldwide, London in 2009. BBC Worldwide is the main commercial arm and a wholly owned subsidiary of the British Broadcasting Corporation [30]. Its mission is to create, acquire, develop and exploit media content and brands around the world in order to maximise the value of the BBC's assets for the benefit of the UK licence payer. The Digi-Hub team was made up of 9 staff: Project Manager, Business Analyst, Software Architect, Tester, Lead Developer, 3 Developers and a Support Developer. It was working on a mix of developing new software and software maintenance. The technology used was C\#, .NET, MS SQL Server, and legacy Connected Service Framework (CSF) code.

In a separate study, [31] examined how the lean ideas behind the Toyota Production System could be applied to software project management. Based on a detailed investigation of the Digi-Hub development team over a 12 month period, the study found that lead time to deliver software improved by $37 \%$, consistency of delivery rose by $47 \%$ and defects reported by customers fell $24 \%$. In summary, their study concluded that the performance of the software development team improved by adopting a lean approach.

The current study is part of a bigger research initiative which involves a multiplecase study design and a quantitative survey. And, since the case of BBC Worldwide provided specific evidence of improvements in quality, productivity, it was deemed 
an appropriate case for testing the theoretical framework developed in the current study. In fact, it was an appropriate example of a critical case which met the conditions for testing a well-formulated theory (i.e., the proposed research model), the outcomes of which might result in confirming, challenging, or extending the theory [27]. Therefore, the main goal of the current study is to test the research model in an attempt to identify additional predictor constructs or variables that might influence agile usage, or avoid inadvertent exclusion of variables in the proposed model. The study analyses the significance of each of the factors on the effectiveness of the usage of agile practices at the team level.

Agile Usage: Usage is a key measure of successful implementation of a Systems Development Methodology in organizations. Since the current study is more interested in how extensively and deeply agile practices are used after adoption rather than its adoption per se, the interpretation of [10] was used to measure usage using the following two measures:

1) Horizontal usage - percentage of projects and developers/analysts using agile practices

2) Vertical usage - extent of use - i.e., maximum intensity of their use, i.e., depth of use of specific agile values, practices, and policies

Agile Usage Effectiveness: Agile effectiveness as a factor affecting agile usage will be measured using three variables: two of these are associated with the successful usage of systems development methodologies and have been identified as the core criteria for assessing post-implementation effectiveness [15, 32]. They are: 1) productivity improvements in the development process, and 2) improved quality of the delivered system. In addition, a third construct, customer satisfaction, which is recognized as a key measure of agile effectiveness in the agile literature $[33,34]$ was used to measure agile effectiveness.

\section{Data Analysis and Findings}

\section{Innovation factors}

Relative advantage: At BBC Worldwide, the Digi-Hub team was delivering enterprise messaging systems, which was very complex, poorly architected with very large and complex legacy code base. The team was initially using Scrum as a methodology when it realized that Scrum's time-boxed iterations were difficult to adhere to in practice, because a piece of work would become a lot bigger once started and the team was not able to visualize many things that they were doing at the same time, and there was reprioritization by the business all the time. The specific advantages of using Kanban in comparison with its precursor method/practices such as Scrum were i) limiting the work in progress, i.e., stopping context-switching and getting efficiency out of visualizing the process and gaining an understanding of the whole process, ii) reducing batch size, i.e., by reducing the size of units of work going through the pipeline overheads are reduced including changes in requirements and iii) 'granularity of visualisation', “. . in Scrum you don't get the granularity of visualisation, Kanban 
is very granular, and what really happens is once you start visualising your work, the whole team gets a collective understanding of how they build software" (Developer, Digi-Hub team).

Compatibility: There were not any major compatibility issues as the team had been using many Scrum and XP technical practices for almost more than 9 months before Kanban was introduced. The team very soon recognised that Kanban was a good fit that matched the contextual requirements of the project requirements and the team.

\section{Sociological factors}

Experience: Team members had high levels of experience and technical competence in software development. Though they were familiar with XP and Scrum practices, no one had used Kanban before. But most team members had the attitude and the willingness to learn and change, and were self-motivated.

Knowledge/Expertise: The team was not familiar with the business domain, but had high levels of technical knowledge and expertise, for example programming languages, Microsoft Stack, Webservices, user interfaces. The rationale was that it is much easier for people with high levels of technical expertise to pick up a new business domain. According to one of the developers, "if you have technical expertise you can usually understand new business domains quickly".

\section{Technological factors}

Agile practices: Though they were a Scrum team which used two-weekly sprint timeboxed iterations, retrospectives, planning meetings etc., when they moved to Kanban they incorporated Kanban properties without making major changes to some of the existing XP/Scrum practices that were working well, for example, daily meetings, refactoring, test-driven development. Therefore deeper and intensive use of agile practices with an emphasis on optimizing the existing process eventually led to a mature implementation of Kanban "we visualised our workflow, limited WIP, we used models, collected data to manage and measure of flow,..i.e, we had all the five properties from David Anderson's book, and we had some of the emergent properties as well" (Developer, Digi-Hub team).

Tool support: A number of technical tools such as Cucumber for automated testing, TeamCity for continous integration were used, and a lot of data was collected from the Kanban board which in conjunction with other internal systems for logging hours etc., were fed into the project management practices.

\section{Team factors}

Team Management: Kanban was implemented at BBC Worldwide during 20082009 which were early days for Kanban with not much literature, but the team worked together by learning from each other and ensured that the strengths and expertise of different members were well reflected in the choice of their tasks and decisions (for example, some members of the team were very strong on test driven development) and had a common understanding of what the team thought good practices were. The team enjoyed a lot of autonomy in terms of being able to make decisions relating to breaking quite a high level problem into smaller chunks, choice of relevant tools, etc. 
Methodology Champion: The role of the methodology champion was not to strictly enforce the technical practices on the team (the team by itself adhered to practices), but rather act as a mentor who facilitated the effective use of kanban practices, and guided the team in the right direction whenever there were major problems or issues.

\title{
Organizational factors
}

Top Management support: The governance structure when the team moved to Kanban in 2008 was:

\author{
Business Board (Strategy \& Budget) \\ Project Board (Detail \& authorise specific work) \\ Product Owner (reconcile Business \& Customer wants) \\ Users requesting work (Sign off work completed) \\ End users (200 - 300 people)
}

The team received very strong support from the Project Board, Product Owner, and IT management, and also in terms of knowledgeable colleagues, and benefited from hearing to world renowned speakers such as Martin Fowler, Craig Larman, David Anderson, etc., come and talk at BBC Worldwide. However, support at the business board level was not as strong due to a lack of understanding of the changes in methodologies and technical practices.

\subsection{Agile Usage and Effectiveness}

\subsubsection{Agile Usage}

Horizontal usage of agile practices at BBC Worldwide increased consistently after the implementation of Kanban. Before Kanban was introduced almost half (50\%) of the projects were using Scrum, and when Kanban was implemented the usage eventually increased to almost $80 \%$. Kanban usage continued to spread widely as other teams (i.e., other than Digi-Hub) also started implementing Kanban. Use of Kanban spread into the BBC from BBC Worldwide, the spread being referred to as Kanban flu. The number of analysts/developers etc working on Kanban projects also increased steadily in almost exactly the same proportion as the number of projects described above. In particular vertical usage was found to play a significant role in determining the effectiveness of usage which is best reflected in words of a developer on the team, "the depth of adoption maps to an exponential curve of success - I think if you just do a couple of practices you are not going to get much benefit. If you do a lot of them and they are deeply engrained you are likely to be more successful"

\subsubsection{Agile Usage Effectiveness}

Usage effectiveness was analyzed using three main factors: improved quality of the development process, improved productivity during the development process, and customer Satisfaction. Specific improvements were recorded based on the data collected between October 2008 and October 2009 (refer to [31] for a detailed investigation and more specific discussion of the results and findings).

Quality: The quality of the development process improved which was measured by the number of live defects (live defects are the bugs reported by customers during a 
week plus the bugs still open). The numbers of live defects reported by customers fell by $24 \%$, i.e., bugs were being fixed more quickly and the mean numbers of bugs open each week also slightly declined.

Productivity: Three important measures were used to measure improvements in productivity: i) lead time: the total elapsed time from when a customer requests software to when the finished software is released to the customer. It tracks how quickly and reliably software is delivered to customers. Lead time to deliver software improved by $37 \%$, and consistency of delivery rose by $47 \%$ ii) development time: this measure gives insight into the efficiency of development. Development time is recorded in working days - variation in delivery times reduced by $78 \%$ from 30.5 to 6.8 , and the mean time to develop fewer and smaller software features declined by $73 \%$ from 9.2 to 2.5 working days. iii) Release Frequency (RF) is defined as the number of items released to customers per month - RF increased by a factor of 8 from 2 in November 2007 to 16 in October 2009.

Customer Satisfaction: The team was customer focused and responsive to customer needs, and was able to respond to the needs of the business by delivering new functionality faster and with more predictability. It was believed that a lot of the team's behaviour was driven by focusing on customer needs and satisfaction, " that's driving a lot of your behaviour as well-so if you are focusing on what the customer receives, then a lot of these practices will start to make more sense - breaking work into smaller units means more frequent feedback from customers which is reflected back into requirements of unstarted work"

\subsubsection{Summary of Findings}

In summary, data analysis from the interviews confirmed that all the factors, i.e., (1) Agile innovation factors (relative advantage, compatibility) (2) Sociological factors (experience level, Knowledge/expertise) (3) Technological factors (agile practices, tool support) (4) Team factors (team management, methodology champion and (5) Organizational factors (top management support) played a significant role in affecting effective usage of agile practices. Both horizontal and vertical usage increased significantly and specific improvements in effectiveness measures were recorded.

Agile innovation factors appeared to be influential in the company's acceptance and continued use of agile practices. The team's high levels of experience, technical knowledge and competence, and working in a collaborative, autonomous and selforganizing team style affected the successful usage of agile practices. The emphasis on deeply adopting all the core properties/practices of Kanban where the change was driven by attempting to optimise the existing process without making major changes to existing workflow, job titles, roles and responsibilities, etc., also played a critical role [35]. The methodology champion's role in actively and vigorously promoting his vision for introducing Kanban and using a variety of influence processes to experiment with and implement the various practices had a significant impact on the overall success of the change process. And given that the methodology champion who acted as the key driver for the entire initiative has left the team, the question for BBC Worldwide is, "will the initiative survive?" Top management support will be crucial to sustain the efforts of such initiatives with a focus on continuous improvement as 
one developer rightly pointed out, "it is about making the system that people work in more productive as opposed to the people working in the system. That's really the key difference- a lot of managers focus on people, whereas continuous improvement is always more effective when you focus on the system.."

In addition, another factor, budget and schedule constraint was identified to affect the effective use of agile practices. The team felt that sufficient budget was needed to take on technical debt, practices to change the system such as budget to support appropriate testing environments, automate deployment, etc., This has been confirmed in another study on the acceptance of XP practices [4] which found that projects with relatively less restriction on budget and delivery schedule afforded a lot of flexibility to the team and enabled a deeper adoption of XP practices compared to teams that had strict schedule and budgetary constraints. This will be further verified in the forthcoming case studies before incorporating it into the final framework.

\section{Conclusions}

Given the obvious limitations of any case study approach including issues relating to generalization of findings, the study does not allow any definite conclusions. Replication of the study in different contexts should provide a cross-case comparison and analysis of the results and add to the generalizability of the findings. In this study, our aim was to develop a theoretical model in order to gain a better understanding of the factors that facilitate effective usage of agile practices. The main goal of the study was to test the research model, and therefore the case of BBC Worldwide which had been using agile practices continually for almost more than two years with specific evidence of improvements in quality, productivity, was deemed an appropriate case for testing the theoretical framework developed in the current study. Though the findings from this study confirm that the various factors identified in the framework play a significant role in affecting the increased and continued use of agile practices, it should be noted that these factors represent general factors conducive to agile usage. However, usage effectiveness or success in certain organizations may be influenced by specific factors or measures not identified in the model.

However, it should be emphasized that this study reports research-in-progress, i.e. only part of a larger flexible design research project which involves multiple case studies and a quantitative survey. Further case studies are planned which will be used to refine the factors identified in the research model. Extant literature on agile research will then be used to design the survey instrument by identifying potential indicators to measure each factor of the model. A world wide survey targeting all agile practitioners will be conducted to finalize the model. The goal of the survey would be to empirically validate the factors and the relationships proposed in the agile usage model and their importance for the overall effective usage of agile practices.

\section{Implications of the Study}

The findings from this study provide important implications for both the research and practitioner communities. 
From a research perspective, the current study draws upon related streams of literature to synthesize the various factors that relate to the effectiveness of agile usage. It focused on identifying factors that may explain agile usage during the later stages of adoption, i.e., the post-adoption stage of usage. The emphasis is on how extensively and deeply the innovation is used after adoption, rather than its adoption per se. In the context of software process innovations, this notion is generally referred to as the innovation's degree of assimilation into the organization [36, 37]. Agile research that focuses on post-adoption and later stages of the assimilation, i.e., usage and routinization of agile practices is emerging. While [24] studied the assimilation of $\mathrm{XP} /$ Scrum practices using three case studies, [4] focused on the acceptance of XP practices across different teams within the same organization. [24] highlight the need to include agile methods other than XP, and the need for a more quantitative approach to determine the levels of ISD usage across the ISD community with more generalisable results. These studies provide some insights into the post-adoption use of specific agile methods/practices such as XP or Scrum. However, there is very limited empirical research that have studied the actual use of agile practices using appropriate theoretical concepts or frameworks [24]. Moreover, the relationship between agile usage and agile effectiveness i.e., usage as a factor affecting effectiveness, has been omitted from this important stream of research. The current study can be seen as a first step in addressing this important gap in the agile extant literature which has developed a theoretical framework by identifying a set of factors that might affect the continued usage of agile practices, where 'usage' refers to the use of agile practices ranging from the use of specific methods/practices such as XP or Scrum to the use of combination of properties/practices from different methods such as XP, Scrum, waterfall, etc.

For the practitioner community, the study has identified i) the important factors that might play a significant role in affecting usage, i.e., both the vertical (intensity of use) and horizontal (spread of use) usage of agile practices, and ii) the effect of usage on effectiveness, i.e., the bi-directional relationship between usage and its effectiveness (improvements in quality, productivity, and customer satisfaction), i.e. the more extensive and deeper the usage the more effective will be its use, and increased effectiveness of agile usage will in turn have an impact on the increased usage of agile practices in the organization. In practice, the results can guide IS managers seeking to propagate the continued use of agile practices for systems development. In general, it is important that managers monitor and evaluate the innovation factors such as relative advantage which will help not only to sustain the effective usage of agile practices but will also enable recognition of any need for change. Since higher levels of technical knowledge and competence, experience, and the willingness to learn and change at the team level are key factors that affect the effective use of agile practices, managers should cultivate such expertise among their staff through effective coaching, training, and technical support programs. Adequate technical support is necessary to overcome resistance and compatibility issues, and impart necessary skills to the development teams. Methodology champions should ensure deeper adoption of all the core agile properties/practices in order to reap the real benefits of effective agile implementation. Top management support will be crucial to sustain the efforts of such initiatives so that the whole organization can evolve to be agile. 


\section{References}

1. Abrahamsson, P., Conboy, K., Wang, X.: Lots done, more to do: the current state of agile systems development research. European Journal of Information Systems 18, 281-284 (2009)

2. Dyba, T., Dingsoyr, T.: Empirical studies of agile software development: A systematic review. Information and Software Technology 50 (2008)

3. Vijayasarathy, L.R., Turk, D.: Agile Software Development: A survey of early adopters. Journal of Information Technology Management 19(2) (2008)

4. Mangalaraj, G., Mahapatra, R., Nerur, S.: Acceptance of software process innovations - the case of extreme programmin. Empirical Software Engineering 18, 344-354 (2009)

5. Kwon, T.H., Zmud, R.W.: Unifying the fragmented models of information systems implementation. In: Critical Issues in Information Systems Research, pp. 227-251. John Wiley \& Sons, Inc., Chichester (1987)

6. Karahanna, E.: Symbolic Adoption of Information Technology. In: Proceedings of Decision Sciences International Conference, Athens, Greece (1999)

7. Boehm, B.: Get Ready for Agile Methods, with Care. IEEE Computer 35(1), 64-69 (2002)

8. Highsmith, J., Cockburn, A.: Agile Software Development: The Business of Innovation. Computer, 120-122 (September 2001)

9. Nerur, S., Mahapatra, R.: Challenges of Migrating to Agile Methodologies. Communications of the ACM 48(5), 73-78 (2005)

10. McChesney, I.R., Glass, D.: Post-implementation management of CASE methodology. European Journal of Information Systems 2(3), 201-209 (1993)

11. Patton, J.: Kanban Development Oversimplified (2009), http: / /www.agileproductdesign.com/blog/2009/ kanban_over_simplified.html [November 27, 2010]

12. Williams, L., Layman, L., Krebs, W.: Extreme Programming Evaluation Framework for Object-Oriented Languages Version 1.4, in NCSU Technical Report (2004)

13. Rogers, E.M.: Diffusion of Innovations, 5th edn. Free Press, New York (2003)

14. Hardgrave, B.C., Davis, F.D., Riemenschneider, C.K.: Investigating Determinants of Software Developers' Intentions to Follow Methodologies. Journal of Management Information Systems 20(1), 123-151 (2003)

15. Huisman, M., Iivari, J.: The Individual Deployment of Systems Development Methodologies. In: Pidduck, A.B., Mylopoulos, J., Woo, C.C., Ozsu, M.T. (eds.) CAiSE 2002. LNCS, vol. 2348, pp. 134-150. Springer, Heidelberg (2002)

16. Rajlich, V.: Changing the paradigm of software engineering. Communications of the ACM 49(8), 67-70 (2006)

17. Hardgrave, B.C., Johnson, R.: Toward an information systems development acceptance model: the case of object-oriented systems development. IEEE Transactions on Engineering Management 50(3), 322-336 (2003)

18. Khalifa, M., Verner, J.: Drivers for Software Development Usage. IEEE Transactions on Engineering Management 47(3), 360-369 (2000)

19. Agarwal, R., Prasad, J.: A Field Study of the Adoption of Software Process Innovations by Information Systems Professionals. IEEE Transactions on Engineering Management 47(3), 295-308 (2000)

20. Pikkarainen, M., Wang, X., Kieran, C.: Agile Practices in Use from an Innovation Assimilation Perspective: A Multiple Case Study. In: Twenty Eighth International Conference on Information Systems, Montreal (2007) 
21. Fitzgerald, B.: The use of systems development methodolgies in practice: a field study. Information Systems Journal 7, 201-212 (1997)

22. Green, G.C., Hevner, A.R., Webb Collins, R.: The impacts of quality and productivity perceptions on the use of software process improvement innovations. Information and Software Technology 47(8), 543-553 (2005)

23. Van de Ven, A.H.: Central Problems in the Management of Innovation. Management Science 32(5), 590-607 (1986)

24. Pikkarainen, M., Wang, X., Conboy, K.: Agile Practices in Use from an Innovation Assimilation Perspective: A Multiple Case Study. In: Twenty Eighth International Conference on Information Systems, Montreal (2007)

25. Sultan, F., Chan, L.: The adoption of new technology: the case of object-oriented computing in software companies. IEEE Transactions on Engineering Management 47(1), 106-206 (2000)

26. Roberts, T.L., et al.: Factors that impact implementing a SDM. IEEE Transactions on Software Engineering 24(8), 640-649 (1998)

27. Yin, R.K.: Case Study Research: Design and Methods. Sage Publications, CA (1994)

28. Benbasat, I., Goldstein, D.K., Mead, M.: The Case Research Strategy in Studies of Information Systems. MIS Quarterly 11(3), 369-386 (1987)

29. Eisenhardt, K.M.: Building Theories from Case Study Research. The Academy of Management Review 14(4), 532-550 (1989)

30. BBCWorldwide (2010), http: / / www . bbcworldwide. com/about-us . aspx

31. Middleton, P., Joyce, D.: Lean Software Development: BBC Worldwide Case Study. In: Lean Software and Systems Conference, Atlanta (2010)

32. Iivari, J.: Why are CASE tools not used? Communications of the ACM 39(10), 94-103 (1996)

33. Cockburn, A., Highsmith, J.: Agile Software Development: The People Factor. Software Management (2001)

34. Misra, S.C., Kumar, V., Kumar, U.: Identifying some important success factors in adopting agile software development practices. The Journal of Systems and Software 82, 18691890 (2009)

35. Anderson, D.: Kanban, Successful Evolutionary Change For Your Technology Business (2010)

36. Fichman, R.G., Kemerer, C.F.: The Assimilation of Software Process Innovations: An Organizational Learning Perspective. Management Science 43(10), 1345-1363 (1997)

37. Gallivan, M.J.: Organizational Adoption and Assimilation of Comlex Technological Innovations: Development of a New Framework. The DATABASE for Advances in Information Systems 32(3), 51-80 (2001) 